\title{
Intraregional propagation of Covid-19 cases in Pará, Brazil: assessment of isolation regime to lockdown- CORRIGENDUM
}

\section{Corrigendum}

Cite this article: da Silva FL, Pita JD, Gomes MDA, Lélis da Silva AP, da Silva GLP (2021). Intraregional propagation of Covid-19 cases in Pará, Brazil: assessment of isolation regime to lockdown- CORRIGENDUM. Epidemiology and Infection 149, e93, 1-1. https://doi.org/ $10.1017 / \mathrm{S} 0950268821000765$
Félix Lélis da Silva ${ }^{1,2}$, Javier Dias Pita ${ }^{1,2}$, Maryjane Diniz A. Gomes ${ }^{1,2}$, Andréa P. Lélis da Silva ${ }^{3}$ and Gabriel Lélis P. da Silva ${ }^{4}$

${ }^{1}$ Federal Institute of Science and Technology of Pará-IFPA Campus Castanhal, Castanhal, Brazil; ${ }^{2}$ Research Groupfor Biosystems Management, Modeling and Experimentation-GEMAbio, IFPA, Castanhal, Brazil;

${ }^{3}$ MetropolitanRegional Hospital-Specialist in Intensive Care Unit, Pará, Brazil and ${ }^{4}$ Central University of Paraguay, Medicineundergraduate student, Cidad del Leste, Paraguay

This article was originally published with a mistake in the third author's name. The correct full name should be "Maryjane Diniz A. Gomes". This has now been corrected in the online version of the article.

There were also several numerical errors in the paragraph titled "Study Area". The corrected version of this paragraph is shown in full below.

The study was carried out in 114 affected municipalities among the 144 existing in the state of Pará, North region, Brazil (Figure 1). The state has a territorial extension of $1,247,698.515 \mathrm{~km}^{2}$ and an estimated population of 7,581,051 people, with 5,191,559 residents in urban areas and $2,389,492$ in rural areas, with a population density of 6.07 inhabitants $/ \mathrm{km}^{2}$ and an average Human Development Index of (HDI = 0.698) (IBGE, 2020).

\section{Reference}

Lélis da Silva, F., Dias Pita, J., Gomes, M. D. A, Lélis da Silva, A. P and Da Silva, G. L. P (2021). Intraregional propagation of Covid-19 cases in Pará, Brazil: Assessment of isolation regime to lockdown. Epidemiology and Infection, 149, E72. doi:10.1017/S095026882100039X
(C) The Author(s), 2021. Published by Cambridge University Press. This is an Open Access article, distributed under the terms of the Creative Commons Attribution licence (http://creativecommons.org/licenses/by/4.0/), which permits unrestricted re-use, distribution, and reproduction in any medium, provided the original work is properly cited.

\section{CAMBRIDGE UNIVERSITY PRESS}

